\title{
MOTILITY DISORDERS
}

Motility Disorders of the Gastrointestinal Tract: Principles and Practice, edited by Sinn Anuras (1992). Raven Press, 1185 Avenue of the Americas, New York, NY 10036; US\$98.

Motility Disorders of the Gastrointestinal Tract, long awaited by gastroenterologists with an interest in teaching gastrointestinal motility, strives to outline objectively what gastrointestinal motility is, how it is controlled and how disorders of gastrointestinal motility may present to the clinician. The book is organized into four parts, with the first part consisting of two chapters on the anatomy and the regulation of gastrointestinal motility. The second part consists of four chapters outlining the techniques of investigating motility in the esophagus, stomach, small intestine and colon. The third part specifically discusses diseases that are felt to have gastrointestinal motility as part of their presentation. Finally, there are four chapters that cover specific motility disorders in the esophagus, stomach, colon and biliary tract.

Overall, the book is very satisfactory and in parts is superb. Particularly, the first two chapters are excellent overviews of the present understanding of the anatomy and physiology of gastrointestinal motility. The least satisfactory chapters are those dealing with specific motility disorders in each organ system as it is obvious our understanding of motility in diseased states is still lagging far behind our understanding of the organization of the gastrointestinal tract. Nevertheless, with the intent of the book to approach gastrointestinal motility disorders objectively, it is clear that many advances have been made, and this book helps to integrate the basic science with the clinical presentation of gastrointestinal motility disorders. The best chapters from a clinical point of view are those dealing with specific disorders such as irritable bowel syndrome and pseudo-obstruction syndromes.

I recommend this book to anyone wanting to understand more about motility disorders of the gastrointestinal tract.

Geoffrey K Turnbull MD FRCPC Associate Professor of Medicine

Dalhousie University Halifax, Nova Scotia 


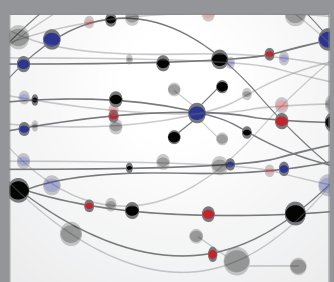

The Scientific World Journal
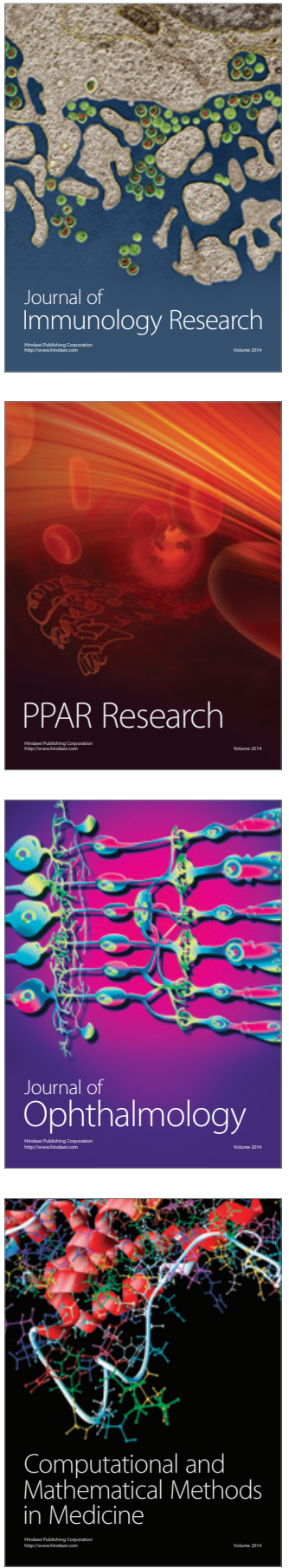

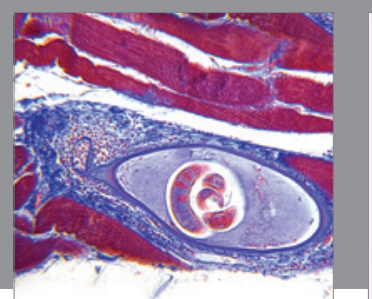

Gastroenterology Research and Practice

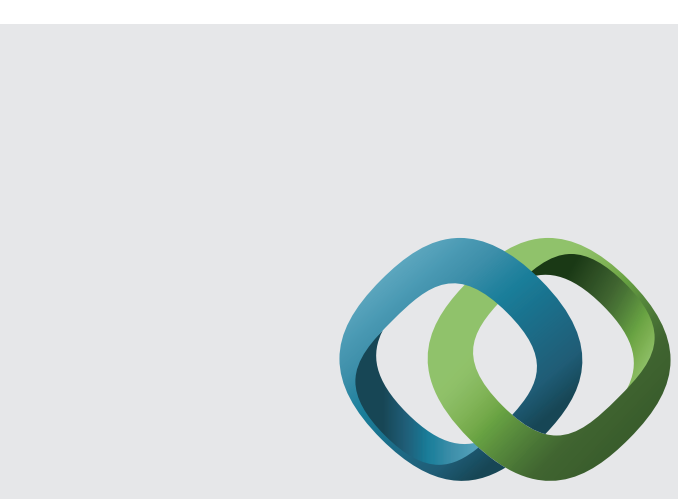

\section{Hindawi}

Submit your manuscripts at

http://www.hindawi.com
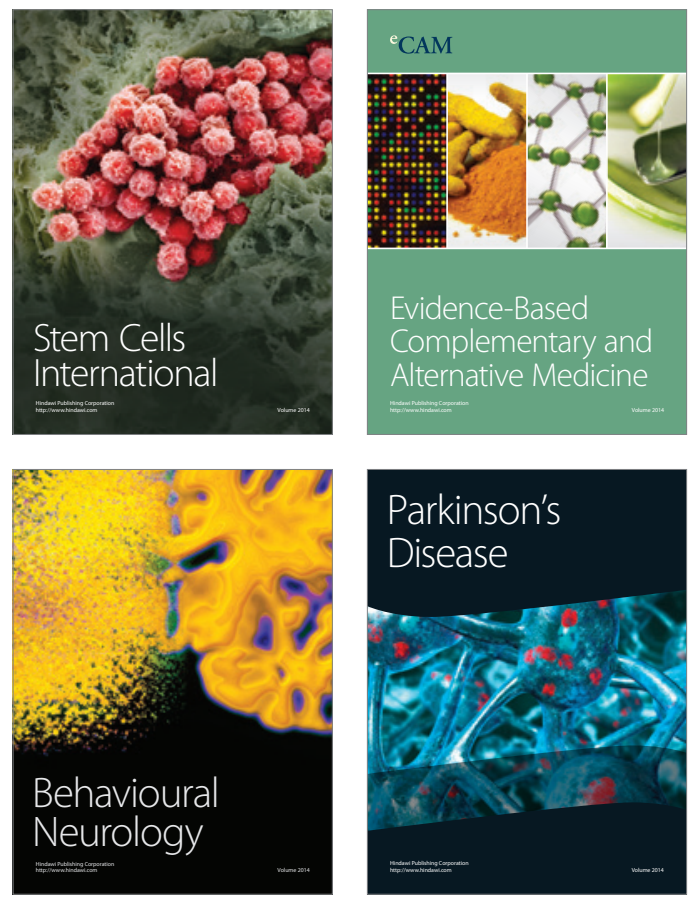
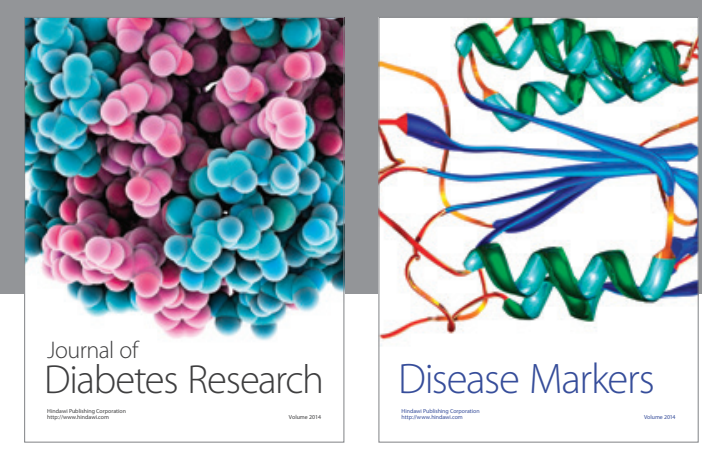

Disease Markers
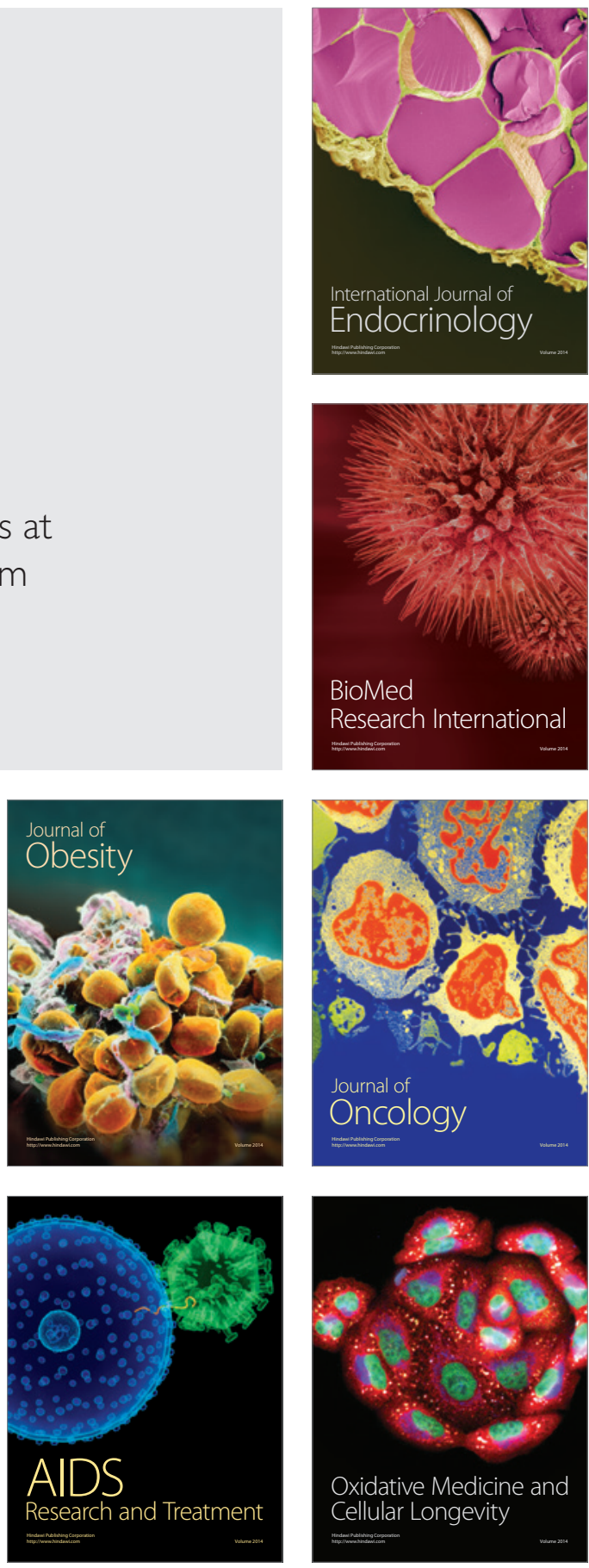